\title{
Copper Removal by Acid-Conditioned Zeolite, Part Ii: Kinetics, and Thermodynamic Studies
}

\author{
Andrés Avelino Abin-Bazaine ${ }^{1} \quad$ Gilberto Sandino Aquino-De Los Ríos ${ }^{1} \quad$ Luis Miguel Rodríguez-Vázquez $^{2}$ \\ Eduardo Santellano-Estrada ${ }^{1} \quad$ Sandra Rodríguez-Piñeros ${ }^{1} \quad$ Leonor Cortés-Palacios ${ }^{*}, 1$ \\ 1.Facultad de Zootecnia y Ecología, Universidad Autónoma de Chihuahua. Perif. Francisco R. Almada Km. 1. \\ Chihuahua, Chih., México \\ 2.Instituto Tecnológico de Parral. Avenida Tecnológico No. 57. Hidalgo del Parral, Chihuahua, México
}

\begin{abstract}
Heavy metal water pollution is one of the most pressing environmental problems of the last decades. Wastewater from many industrial processes contain high concentrations of metals and have very acid $\mathrm{pH}$. Thus, technologies to remove heavy metals from aqueous solutions are costly or suffer deterioration when in contact with substances with acid $\mathrm{pH}$. Natural zeolites have demonstrated to be a low-cost heavy metal adsorbent. This study aimed to determine basic parameters for efficient copper removal by aluminosilicates. A Zeolite was conditioned with concentrated $\mathrm{H}_{2} \mathrm{SO}_{4}$ to further develop the experiments to test 4 kinetics (Pseudo-first-order, Pseudo-second-order, Elovich and Webber-Morris) and to calculate thermodynamic parameters $\left(\Delta \mathrm{G}^{\circ}, \Delta \mathrm{H}^{\circ}, \Delta \mathrm{S}^{\circ}\right.$ and Ea). Out of the studied kinetic models, the one that best correlated was the Pseudo-second order model. According to thermodynamic studies, the increase in temperature favors adsorption and the process is spontaneous.
\end{abstract}

Keywords: Kinetics, Thermodynamic, Aluminosilicates, Metals, Pseudo-second-order.

DOI: $10.7176 / \mathrm{JEES} / 9-3-04$

Publication date:March $31^{\text {st }} 2019$

\section{Introduction}

Heavy metal pollution is one of the most important environmental problems of recent decades (Abdolali et al., 2016). These are pollutants that are not biodegradable, but they tend to bioaccumulate in the food chains resulting in a high risk to human health (Hamidpour et al., 2010). One of the most challenging environmental problems of numerous mining operations is the production of acid mine drains (AMD) (Kaur, Couperthwaite, Hatton-Jones, \& Millar, 2018), especially where coal and gold mine activities are common (Kefeni, Msagati, \& Mamba, 2017). Mining is an essential industry for the development of emerging economies, but it generates huge amounts of waste. Acid mine drainages (AMD) are a serious environmental problem faced by mining companies around the world, due to their extremely low pH values (pH less than 3) and their high content of heavy metals (I. Park et al., 2018; Ryu et al., 2019). AMD is one of the most important forms of water pollution in the world and the USA Environmental Protection Agency (US-EPA) considers that it is only located after global warming and ozone depletion in terms of ecological risk. Many methods used for AMD remediation have limited implementation due to poor performance, inaccuracies in design, difficult functionality, high costs, use of hazardous chemicals, depletion of natural resources and generation of more waste. As a result of these limitations and due to the need for sustainability, research is being done on the use of alternative materials for the treatment of AMD (V. K. Gupta, 2015; Moodley, Sheridan, Kappelmeyer, \& Akcil, 2018). The USA Environmental Protection Agency (US-EPA) (Environmental Protection Agency, 2014) stated that such methods involve large amounts of capital for equipment and / or operating costs; also they are not very effective to remove heavy metals that are in concentrations of a few ppm (V. K. Gupta, 2015). Once the AMD is generated, appropriate remediation techniques should be used, in order to minimize negative environmental impacts mainly in the receiving water bodies and ecosystems (Kefeni et al., 2017; I. Park et al., 2018). The use of biosorbents to remove heavy metals or to recover valuable metals from an aqueous solution is one of the most recent developments in environmental technologies and bioremediation technologies (Kim, Park, \& Park, 2015; J. H. Park et al., 2016). The use of natural materials that can be found locally in a region can be used as bioadsorbents since they have the ability to bind heavy metals. A significant advantage of zeolites is their ability to adsorb cations. In several previous studies the ion exchange affinity of zeolites for the extraction of metals from wastewater solutions has been described (Ryu et al., 2019). Zeolites are minerals of hydrated aluminosilicates. The structure of the zeolites consists of a three-dimensional lattice of tetrahedra of $\mathrm{SiO}^{+4}$ and $\mathrm{AlO}^{+4}$ (Abdel Salam, Reiad, \& ElShafei, 2011). Malamis and Katsou (2013) affirmed that several factors had an influence on the process of adsorption of heavy metals by means of zeolites. Kinetic studies are very important because they provide the minimum information necessary for the design of a heavy metal removal technology through the modeling and simulation of the adsorption process (Motsi, Rowson, \& Simmons, 2011). In Mexico, large deposits of Zeolites are found and present relatively low costs compared with other types of adsorbents, therefore the use of these as a treatment for acid mine drainages represents an adequate economic option. Several kinetic models have been used to describe the mechanisms of the adsorption process (Abdel Salam et al., 2011; Ghasemi, Javadian, Ghasemi, Agarwal, \& Kumar, 2016; V. K. Gupta, Mittal, \& Mittal, 2012; Kim et 
al., 2015; Li et al., 2015; Malamis \& Katsou, 2013; D. Park, Yun, \& Park, 2010; Shukla, Wang, Ang, \& Tadé, 2009). Industrial acid drainages have very acidic $\mathrm{pH}$ values, which can affect the adsorption capacity of a zeolite by modifying the exchange sites of the zeolite surface. Solution $\mathrm{pH}$ affects both aqueous chemistry and surface binding of the adsorbent (Demiral \& Güngör, 2016). The objective of the present work was to determine the adsorption capacity of copper by means of zeolites that was subjected to an acid activation. The results will help design innovative technologies for heavy metal removal.

\section{Materials and Methods}

2.1 Reagents

The $\mathrm{Cu}(\mathrm{II})$ standard solution was prepared with Penta Hydrated Copper Sulphate $\left(\mathrm{CuSO}_{4} \cdot 5 \mathrm{H}_{2} \mathrm{O}\right)$, reactive grade with distilled water.

\subsection{Preparation of the adsorbent material}

Natural zeolite obtained from the Chihuahua region of México was modified by an immersion in concentrated sulfuric acid $\left(\mathrm{H}_{2} \mathrm{SO}_{4}\right)$ for 24 hours, after conditioning they were decanted and washed with distilled water and dried in an oven. The samples were crushed and passed through a metal sieve with an opening of $2 \mathrm{~mm}$.

\subsection{Characterization of the adsorbent material}

Chemical Composition of the Zeolites in the solids were determined by analytics methods: inductively coupled plasma optical emission spectroscopy (ICP-OES) on Thermo Scientific iCap 6500 DUO (USA). Table 1 show the chemical composition. Used Hitachi Scanning Electron Microscope SU 3500, vacuum 60 Pa, Accelerating Voltage $15 \mathrm{KV}$, Magnification 250x obtain micrography of zeolites without and with acid treatment to determine if the surface of the material had suffered any damage. Figure 1 show the zeolite without treatment and Figure 2 with treatment.

Table1. Chemical composition of the zeolites

\begin{tabular}{|c|c|}
\hline $\mathrm{SiO}_{2}(\%)$ & 76.49 \\
\hline $\mathrm{Al}_{2} \mathrm{O}_{3}(\%)$ & 9.56 \\
\hline $\mathrm{CaO}(\%)$ & 1.49 \\
\hline $\mathrm{Fe}_{2} \mathrm{O}_{3}(\%)$ & 1.02 \\
\hline $\mathrm{K}_{2} \mathrm{O}(\%)$ & 1.23 \\
\hline $\mathrm{MgO}(\%)$ & 0.72 \\
\hline $\mathrm{MnO}(\%)$ & 0.04 \\
\hline $\mathrm{Na}_{2} \mathrm{O}(\%)$ & 0.25 \\
\hline $\mathrm{TiO}_{2}(\%)$ & 0.15 \\
\hline
\end{tabular}



Figure 1. Microphotograph to Zeolite without treatment 


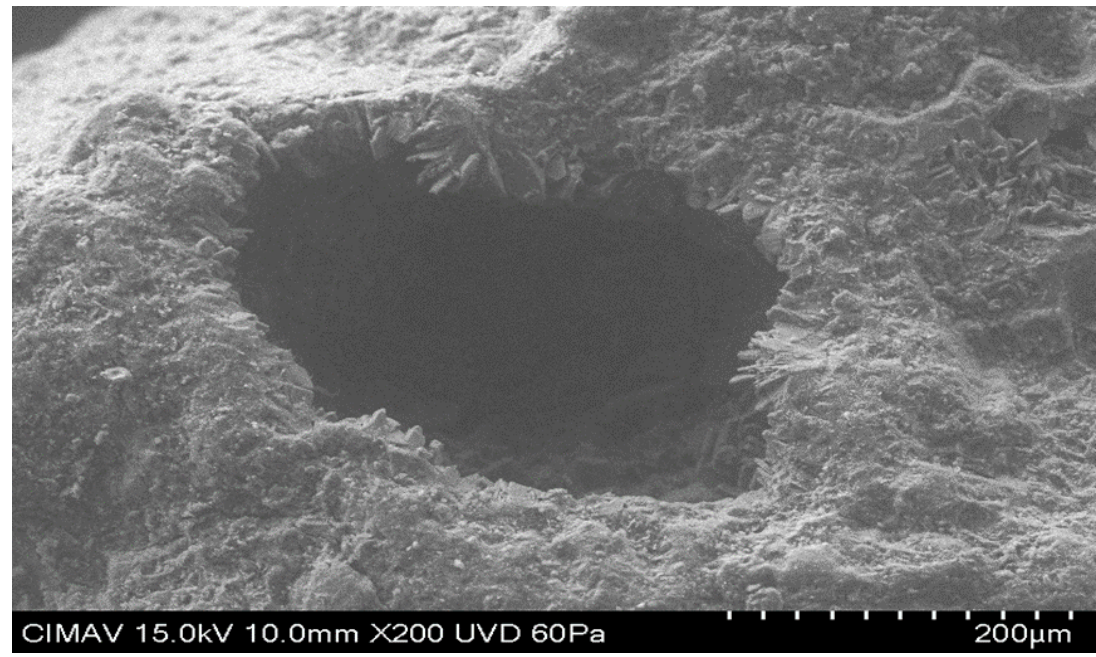

Figure 2. Microphotographs to Zeolite with treatment

\subsection{Methodology}

All laboratory material was presoaked with $5 \% \mathrm{HNO}_{3}$, then rinsed with distilled water and dried in the oven at 106 ${ }^{0} \mathrm{C}$. Batch adsorption experiments were carried out in glass flasks $(0.150 \mathrm{~L})$ using a magnetic shaker at $25^{\circ} \mathrm{C}$ at a constant agitation of $125 \mathrm{rpm}$. The $\mathrm{pH}$ values were adjusted with $\mathrm{HNO}_{3}$ and $\mathrm{NaOH} 0.1 \mathrm{~N}$ and $0.01 \mathrm{~N}$. The $\mathrm{pH}$ values were adjusted so that according to a diagram of chemical species versus $\mathrm{pH}$ values the predominant species was copper ${ }^{2+}$ (Puigdomenech, 2000). Once the test was finished, the samples were separated on Number 1 Whatman filter paper. The concentration of residual metals was measured by ICP-OES Perkin Elmer OPTIMA 8300. The percentage of removal was calculated with the following expression:

$$
\begin{aligned}
& \% \text { Re moval }=\frac{C i-C f}{C i} * 100 \\
& q e=\frac{C i-C f}{m} * V
\end{aligned}
$$

Where: $C_{i}$ and $C_{f}$ are the initial and final concentrations respectively $\left(\mathrm{mg} \mathrm{L}^{-1}\right)$, qe is the sorption capacity of the metal (adsorbate) by the zeolitic material $\left(\mathrm{mg} \mathrm{g}^{-1}\right), \mathrm{m}$ is the mass of the zeolitic material $(\mathrm{g})$ and $\mathrm{V}$ is the volume of the metal ion solution (L) (Fardjaoui, El Berrichi, \& Ayari, 2017; Kankrej, Kulkarni, \& Borhade, 2017; Subramani \& Thinakaran, 2017; Wu \& Wang, 2016).

\subsection{Kinetics and Thermodynamics Studies}

\subsubsection{Effect of contact time}

A 4-level, 3-repetition one-way experimental treatment test was performed. The contact time values used were 30 , 60,90 and $120 \mathrm{~min}$. To a $100 \mathrm{~mL}$ volume at a concentration of $150 \mathrm{mg} \mathrm{L}^{-1} \mathrm{Cu}(\mathrm{II}), 3 \mathrm{~g}$ of the adsorbent material was added. The $\mathrm{pH}$ was adjusted to the range 4.0-4.5.

2.5.2 Effect of Temperature

A 3-level, 3-repetition one-way experimental treatment test was performed. To $100 \mathrm{~mL}$ of a solution at a concentration of $100 \mathrm{mg} \mathrm{L}^{-1}$ was added $3 \mathrm{~g}$ of the adsorbent material. The $\mathrm{pH}$ was adjusted to the range 4.0-4.5 and agitated for 24 hours. Temperature values used were $292.95,309.15$ and $330.15^{\circ} \mathrm{K}$.

\section{Results and Discussion}

\subsection{Effect of Contact Time, and Temperature}

Figure 3 shows the equilibrium conditions. A one-way Analysis of variance of the results obtained in time 90 and 120 minutes is presented in Table 2. As it can be seen in the results, the hypothesis is accepted that the means between these times is equal from the statistical point of view and therefore it can be affirmed that at 90 minutes the equilibrium has been reached.

$$
\begin{aligned}
& \mathrm{H}_{0}: \mu_{90} \quad \mu_{120} \\
& \mathrm{H}_{\mathrm{a}:} \mu_{90}=\mu_{120} \\
& \alpha=0.05 \\
& \text { P-value }>0.05 \text {, accept } \mu_{90}=\mu_{120}
\end{aligned}
$$

The contact time to reach equilibrium was 90 minutes for this study, which is very similar to the findings of Hesnawi, et. al. (2017), similar to the 140 minutes reported by Abdel Salam et. al. (2011); in another study the contact time for equilibrium was 60 minutes (Ltaief, Siffert, Fourmentin, \& Benzina, 2015). Taamneh and Sharadqah (2017) placed equilibrium time in 20 minutes; Ksakas et. al. (2018) found that equilibrium time was 180 minutes; Kocaoba et. al. (2007) found that equilibrium time was 80 minutes. 




Figure 3. Equilibrium conditions

Table 2. One-way analysis of variance of equilibrium conditions.

\begin{tabular}{|c|c|c|c|c|c|c|}
\hline $\begin{array}{c}\text { Source of } \\
\text { Variation }\end{array}$ & $\begin{array}{c}\text { Sum of } \\
\text { Squares }\end{array}$ & $\begin{array}{c}\text { Degree of } \\
\text { Freedom }\end{array}$ & $\begin{array}{c}\text { Mean } \\
\text { Squares }\end{array}$ & F-value & P-value & F-critic \\
\hline $\begin{array}{c}\text { Between } \\
\text { Groups }\end{array}$ & 0.000201 & 1 & 0.000201 & 0.27 & 0.63 & 7.71 \\
\hline $\begin{array}{c}\text { Within } \\
\text { Groups }\end{array}$ & 0.00294 & 4 & 0.000735 & & & \\
\hline Total & 0.00314 & 5 & & & & \\
\hline
\end{tabular}

In the present study it was observed that increasing the temperature increased the adsorption of copper, which is consistent with what was observed by Panayotova (2001). The effect of temperature is a significant physicalchemical parameter, since temperature can change the capacity of adsorption. If the capacity of adsorption increases with increasing temperature, the adsorption process is endothermic (Al-Degs, El-Barghouthi, El-Sheikh, \& Walker, 2008; Santos et al., 2017; Yagub, Sen, Afroze, \& Ang, 2014). This may be due to the increased mobility of the adsorbate molecules and a possible increase in the number of exchange sites (Malamis \& Katsou, 2013; Yagub et al., 2014).

The temperature is related to the kinetic energy of the metal ions in the solution. By increasing it, it results in an increase in the range of diffusion of sorbate. Generally, as the temperature increases, the metal uptake increases due to an increase in the affinity of the adsorbent for these ions and/or an increase in the active sites of the solid. A high temperature increases the energy of the system facilitating the fixation of the metal on the surface of the solid. An increase in temperature results in changes related to both kinetics and equilibrium, which can be attributed to: (i) an increase in kinetic energy, which facilitates the access of metal ions to the exchange sites, (ii) an increase of activity of the solid, which leads to a high affinity or increase in the activity of the exchange sites, and (iii) a decrease in the resistance to mass transfer. As the temperature increases, the thickness of the boundary layer surrounding the solid decreases, facilitating the diffusion of the metal in the solid. Therefore, the effective diffusion coefficient of solid phase ions generally increases and an increase in external mass transport is observed. As the temperature increases, the electro-static interactions become weaker and the ions become smaller because the solvation is reduced. However, if the temperature increases drastically, physical damage can occur on the surface of the solid, reducing its adsorption capacity. In the vast majority of cases, it is very convenient to evaluate the sorption capacity of minerals at room temperature, since maintaining a high temperature will cause a considerable increase in the operating costs of the process (Malamis \& Katsou, 2013).

\subsection{Adsorption Kinetics}

The adsorption kinetics reflects the evolution of the adsorption process versus time (Moussout, Ahlafi, Aazza, \& Maghat, 2018). Chemical kinetics is the study of rates of chemical processes and factors that influence on them in the attainment of equilibrium in a reasonable amount of time. The reaction rate for a given chemical reaction is the measure of the change in concentration of the reactants or the change in concentration of the products per unit time (Chang \& Goldsby, 2013). Two vital evaluation elements for an adsorption process operation unit are the mechanism and the reaction rate. Solute uptake rate determines the residence time required for completing the adsorption reaction and can be obtained from kinetic analysis (Yuh Shan Ho, 2004). When trying a solution for a 
pollution issue by means of an adsorption method, the adsorbent must have not only a suitable adsorption capacity but also as quick an adsorption speed as possible (Subramani \& Thinakaran, 2017).

In order to examine the mechanism that controls the adsorption process, some kinetic models have been used to test the concordance of the experimental data. Four kinetic models were used for this study: Pseudo-first-order, Pseudo-second-order, Elovich and the kinetic model of Intra-particle diffusion.

3.2.1 Pseudo-First-Order Kinetic Model

When the concentration of one relative reactant remains constant because it is supplied in excess, its concentration can be expressed at a constant rate, obtaining the pseudo first order reaction constant, because in fact concentration depends on only one of the two reactants (Chang \& Goldsby, 2013). The pseudo-first order kinetics was found to be suitable for only the initial 20 to 30 minutes of interaction time and not for the whole range of contact times (Y S Ho \& Mckay, 1998). A first-order reaction is a reaction that proceeds at a rate that depends linearly on only one reactant concentration. Pseudo-first order kinetic model indicates that the reaction tends towards physisorption. The name physisorption was given since the rate-limiting step in this kind of mechanism is diffusion and it does not depend on the concentrations of both reactants (physical exchange).

This model is described with a non-reversible reaction:

$$
Z+M \rightarrow Z M
$$

Where: $\mathrm{Z}$ is adsorption sites in the zeolite, $\mathrm{M}$ is the adsorbate and $\mathrm{ZM}$ is the concentration of adsorbate bound to the sorbent

This kinetic equation is based on 4 assumptions:

1. Sorption only occurs at localized sites and there is no interaction between the sorbed ions.

2. The energy of adsorption is not dependent on surface coverage.

3. Maximum adsorption corresponds to a saturated mono-layer of adsorbates on the adsorbent surface.

4. The concentration of $\mathrm{M}$ is considered constant (Largitte \& Pasquier, 2016).

Its expression is the following:

$$
\frac{d q t}{d t}=K_{1}(q e-q t)
$$

Where: $\mathrm{qt}$ is the amount of copper ions adsorbed at time $\mathrm{t}\left(\mathrm{mg} \mathrm{g}^{-1}\right), \mathrm{t}$ is the time (minutes) and $\mathrm{k}_{1}$ is the constant of the adsorption range $\left(\mathrm{L} \mathrm{min}^{-1}\right)$.

The equation of the pseudo first order model can be expressed in linear form with the following:

$$
\log (q e-q t)=\log q e-K_{1} t
$$

The values of qe and $\mathrm{k}_{1}$ are calculated from plotting the slope and the intercept respectively $\log (\mathrm{qe}$-qt) versus $\mathrm{t}$ (Demiral \& Güngör, 2016; Fardjaoui et al., 2017; Feng, Guo, \& Liang, 2009; Kankrej et al., 2017; Rajabi et al., 2016; Song, Wang, Chen, Zhang, \& Dong, 2009; Subramani \& Thinakaran, 2017; Wu \& Wang, 2016; Yari et al., 2015; Zhang, Jin, Shen, Lynch, \& Al-Tabbaa, 2018). Figure 4 shows the performance of this model.

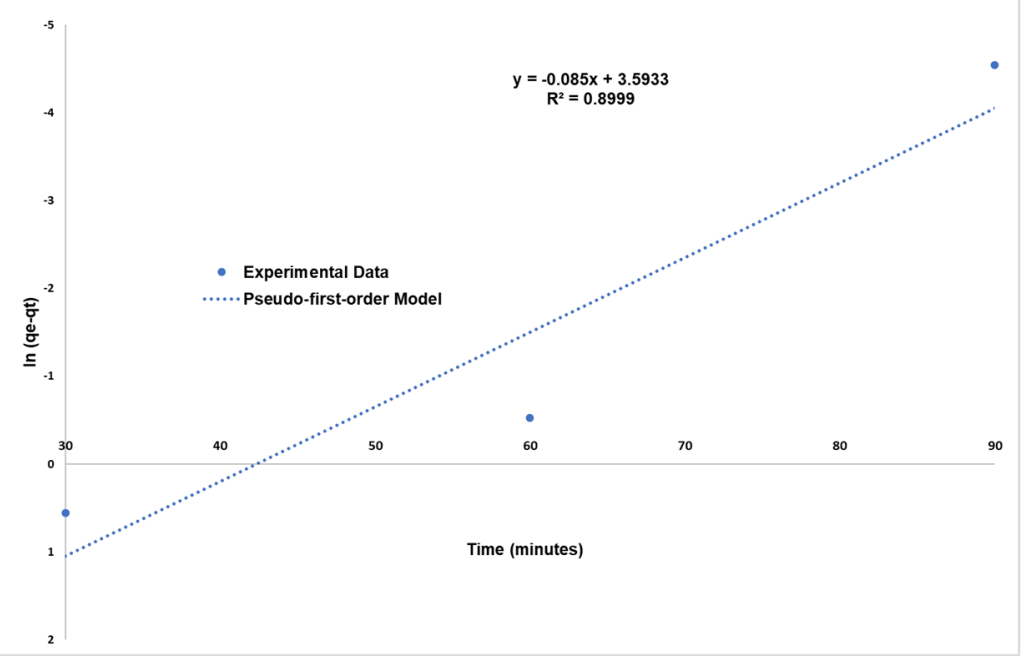

Figure 4. Pseudo-First-Order Kinetics Model for $\mathrm{Cu}$ (II) onto Zeolite 
Table 3. Kinetics model constants and correlation coefficients for $\mathrm{Cu}(\mathrm{II})$ onto Zeolite

\begin{tabular}{|c|c|c|c|c|c|c|c|c|c|c|c|}
\hline $\begin{array}{l}\text { Temp } \\
\left({ }^{\circ} \mathrm{K}\right)\end{array}$ & \multicolumn{3}{|c|}{ Pseudo-First-Order } & \multicolumn{6}{|c|}{ Pseudo-Second-Order } & \multicolumn{3}{|c|}{ Elovich Model } & \multicolumn{2}{c|}{ Intra-particle Model } \\
\hline \multirow{2}{*}{293} & $\mathrm{k}_{1}$ & $\mathrm{q}_{\mathrm{e}}$ & $\mathrm{R}^{2}$ & $\mathrm{k}_{2}$ & $\mathrm{q}_{\mathrm{e}}$ & $\mathrm{R}^{2}$ & $\alpha$ & $\beta$ & $\mathrm{R}^{2}$ & $\mathrm{k}_{\mathrm{p}}$ & $\mathrm{R}^{2}$ \\
\cline { 2 - 12 } & -0.085 & 3.59 & 0.899 & 0.15 & 7.29 & 0.9995 & 1.58 & -2.87 & 0.9987 & 0.43 & 0.988 \\
\hline
\end{tabular}

3.2.2 Pseudo-Second-Order Kinetic Model

In this type of reactions there are two possibilities: the speed can be proportional to the product of two equal initial concentrations, or to the product of two different concentrations (Chang \& Goldsby, 2013). Pseudo second order model expresses that the chemical reaction seems significant in the rate-controlling step. In this type of reactions, the speed is controlled chemically and due to this it is called chemisorption. Pseudo second order model indicates an inclination towards chemisorption.

The kinetic equation of pseudo second order is expressed by the following (Largitte \& Pasquier, 2016):

$$
2 Z+M \rightarrow M(Z)_{2}
$$

Pseudo-second order kinetics, where the rate-limiting step may be chemical adsorption involving valency forces through sharing or exchange of electrons between the adsorbent and sorbate. Pseudo-second-order kinetic model implies that the predominant process here is chemisorption (Demiral \& Güngör, 2016).

The kinetic model of pseudo second order is expressed as:

$$
\frac{d q t}{d t}=K_{2}(q e-q t)^{2}
$$

Where: $\mathrm{K}_{2}$ is the pseudo second order constant $\left(\mathrm{g} \mathrm{mg}^{-1} \mathrm{~min}^{-1}\right)$.

The linear form of this model is expressed as follows:

$$
\frac{t}{q t}=\frac{1}{K_{2} q_{e}^{2}}+\frac{t}{q e}
$$

The values of qe and $\mathrm{k}_{2}$ can be calculated from the slope and the intercept respectively by graphing $t / q t$ versus $t$ (Figure 5) (Demiral \& Güngör, 2016; Erdem, Özcan, Gök, \& Özcan, 2009; Fardjaoui et al., 2017; Feng et al., 2009; Kankrej et al., 2017; Özcan, Erdem, \& Özcan, 2004; Rezaei, 2016; Subramani \& Thinakaran, 2017; Wu \& Wang, 2016; Zhang et al., 2018).

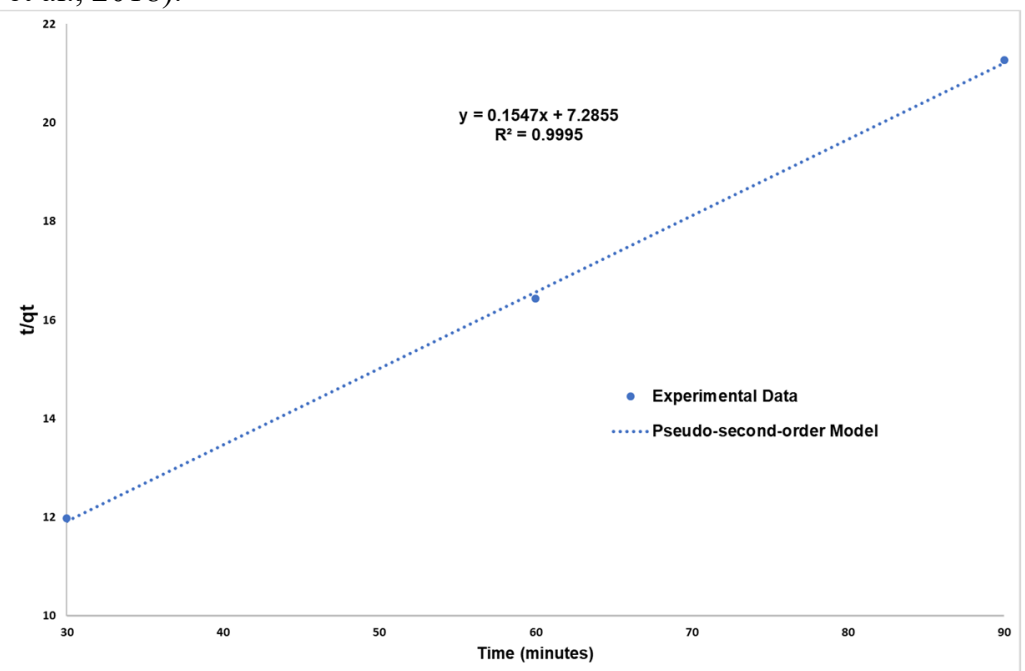

\subsubsection{Elovich Kinetic Mode}

Figure 5. Pseudo-Second-Order Kinetic Model for Cu(II) onto Zeolite

This model assumes that the surface of the solid has a heterogeneous energetic behavior and that neither the desorption nor the interactions between the adsorbed species have a substantial effect on the adsorption kinetics as long as the coverage of the surface of the solid is low. For a very long adsorption time, that is, where time tends to infinity $(t \rightarrow \infty)$, the non-physical behavior of the Elovich equation can be presented, this is due to the fact that the desorption process occurs simultaneously with the adsorption. Therefore, in practice, the applicability of this equation is restricted to the initial part of the interaction process between the adsorbent and the adsorbate, that is when the system is relatively far from reaching equilibrium. It has been shown quantitatively that the Elovich equation and pseudo second order behavior are almost equal when the surface coverage of the solid is less than 0.7 (S. S. Gupta \& Bhattacharyya, 2011). Elovich equation is occasionally used to analyze data, it illustrates the fact that adsorption kinetics can be extremely slow, to such an extent that it seems never to reach equilibrium (Douven, Paez, \& Gommes, 2015).

The Elovich equation is useful in chemical adsorption processes and is suitable for systems with 
heterogeneous adsorption surfaces. The equation of the Elovich model is expressed as follows:

$$
\frac{d q t}{d t}=\alpha_{E} e^{-\delta q t}
$$

Where: $\alpha_{\mathrm{E}}$ is the initial adsorption rate $\left(\mathrm{mg} \mathrm{g}^{-1} \mathrm{~min}^{-1}\right), \delta$ is the desorption constant related to surface coverage and activation energy of chemisorption $\left(\mathrm{g} \mathrm{mg}^{-1}\right)$. The linear form of the equation is given by:

$$
q t=\delta \ln \left(\alpha_{E} \delta\right)+\delta \ln (t)
$$

The Elovich coefficients $\delta$ and $\alpha_{\mathrm{E}}$ were calculated from the intersection and slope respectively by plotting qt vs $\ln$ (t) (Figure 6) (Demiral \& Güngör, 2016; Subramani \& Thinakaran, 2017).

3.2.4 Weber-Morris Intra-Particle Diffusion Model

The mass transfer process has an impact on the adsorption equilibrium time. The mass transfer process generally involves four steps: transport from the bulk solution to the boundary layer, film (boundary layer) diffusion, intraparticle (pore and surface) diffusion and adsorption on the interior surface of adsorbents. It is generally accepted that the first and last steps are very fast and the overall adsorption process is controlled by film diffusion and/or intra-particle diffusion (Zhang et al., 2018).

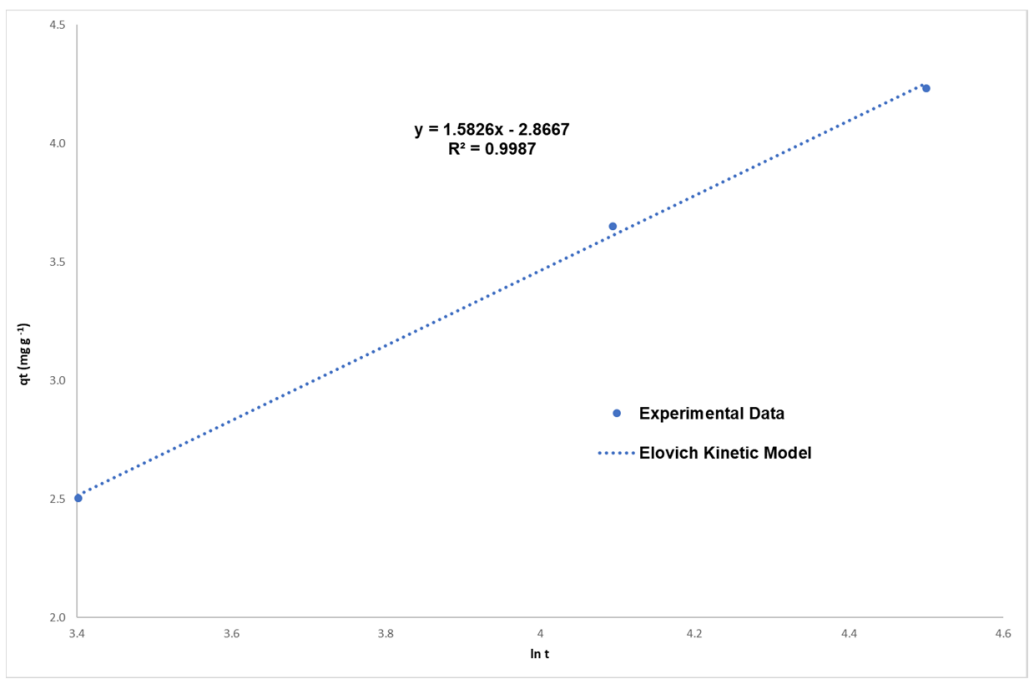

Figure 6. Elovich kinetic model for $\mathrm{Cu}$ (II) onto Zeolite

After the film diffusion process, the adsorbate species are transported to the solid phase through intra-particle diffusion/transport process. Weber and Morris model is used to describe the process of intra-particle diffusion (Zhang et al., 2018).

The adsorption process on a porous adsorbent will generally be a multi-step process. These steps involve the transport of the adsorbate from the bulk solution, the diffusion of the film, the intra-particle diffusion in the pores and in the solid phase and finally the adsorption in the sites. After the film diffusion process, the adsorbate species are transported to the solid phase through intra-particle diffusion/transport process. Weber and Morris model was used to describe the process of intra-particle diffusion (Zhang et al., 2018).

Intra-particle diffusion can be established by the following equation:

$$
q t=K_{p} t^{\frac{1}{2}}
$$

Where: $\mathrm{K}_{\mathrm{p}}$ is the intra-particle diffusion constant $\left(\mathrm{g} \mathrm{mg}^{-1} \mathrm{~min}^{-0.5}\right)$.

The value of $\mathrm{K}_{\mathrm{p}}$ is calculated from the slope of graphing qt versus $\mathrm{t}^{1 / 2}$ (Demiral \& Güngör, 2016; Kankrej et al., 2017; Subramani \& Thinakaran, 2017; Yari et al., 2015; Zhang et al., 2018) (Figure 7). 


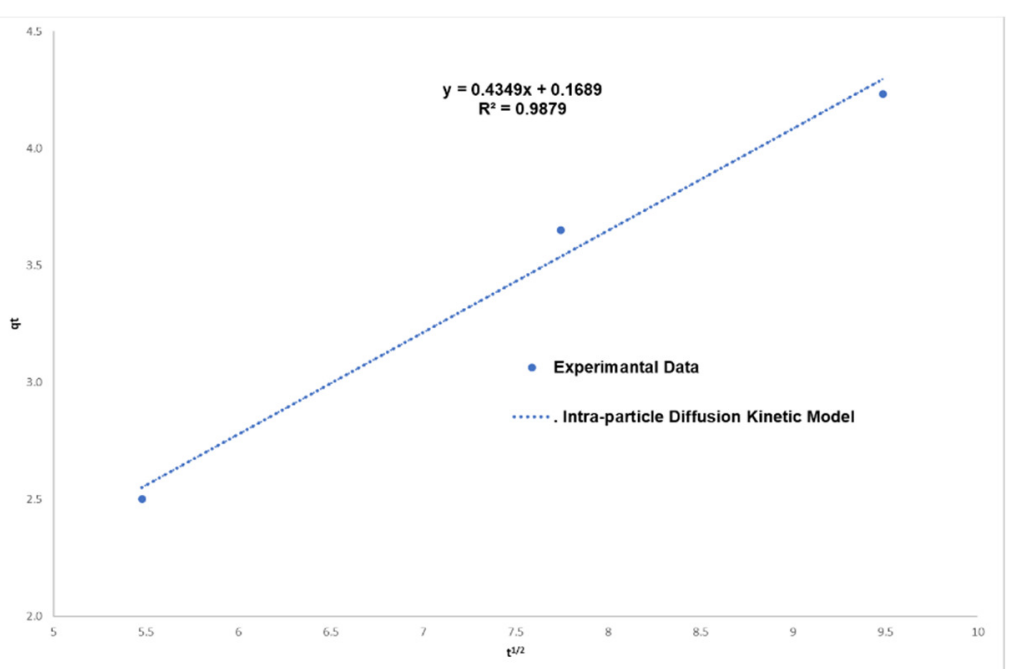

Figure 7. Intra-particle Diffusion Kinetic Model for $\mathrm{Cu}(\mathrm{II})$ onto Zeolite

The value of $\mathrm{R}^{2}$ in Pseudo-first-order model is not acceptable (Table 3), this model has the lowest correlation of the models used for this study. Zanin et. al. (2017) (Zanin et al., 2017) determined that the kinetic model that best correlated, in their adsorption experiment with zeolite, was that of Pseudo-first order, while in this study it was Pseudo-second order. Table 3 show the high degree of correlation of the Pseudo-second-order model, this being the best model used. In our results it was demonstrated that the kinetic model that correlated best was that of Pseudo-second order, being congruent with that obtained by Taamneh and Sharadqah (2017) and Ksakas et. al. (2018). Elovich kinetic model shows a satisfactory correlation but is inferior to another model (Table 3). In a reaction involving more than one reacting species, deliberate attempt may be made for the concentration of one of the reactants to be largely in excess compared to the other one, in such situation, the concentration of the reacting species present in large excess will not change significantly i.e it will remain constant and as a result the rate of the reaction will not depend on such reactant. If such reaction is supposed to be second order, it becomes a pseudo first order and if such reaction is supposed to be third order, it becomes pseudo second order. In summary, a pseudo order reaction is the experimental order which is different from the actual order. Low concentration of solute leads to first order while high concentration of solute leads to chemical bonding and chemisorption. Chemisorption (or chemical adsorption) is adsorption in which the forces involved are valence forces of the same kind as those operating in the formation of chemical compounds. Adsorption process appears as a physical adsorption process, while on the basis of the Pseudo-second-order model adsorption appears to be governed by chemi-adsorption. This contradiction is only apparent given that the adsorption process could be a combination of more than one process: physical adsorption, chemical adsorption, and mass balance. In our case, the physical adsorption is the main step as proved by D-R model, while the Pseudo-second-order equation determined a chemical sorption.

\subsection{Adsorption Thermodynamics}

Gibbs free energy change $\left(\Delta \mathrm{G}^{\circ}\right)$, the standard enthalpy change $\left(\Delta \mathrm{H}^{\circ}\right)$ and the standard entropy change $\left(\Delta \mathrm{S}^{\circ}\right)$ were used to speculate on the adsorption mechanism. These thermodynamic parameters are determined using the following equations:

$$
\begin{gathered}
K_{c}=\frac{C_{A}}{C e} \\
\Delta G^{\circ}=-R T \ln K c \\
\Delta G^{\circ}=\Delta H^{\circ}-T \Delta S^{\circ} \\
\ln K c=\frac{\Delta S^{\circ}}{R}-\frac{\Delta H^{\circ}}{R} \frac{1}{T}
\end{gathered}
$$

Where: $\mathrm{Kc}$ is the equilibrium constant, $\mathrm{C}_{\mathrm{A}}$ is the equilibrium concentration in the solid phase $\left(\mathrm{mg} \mathrm{L}^{-1}\right), \mathrm{Ce}$ is the equilibrium concentration in the liquid phase $\left(\mathrm{mg} \mathrm{L}^{-1}\right), \mathrm{T}$ is the temperature in Kelvin degrees (Fardjaoui et al., 2017; Kankrej et al., 2017; Oren \& Kaya, 2006; Subramani \& Thinakaran, 2017; Wu \& Wang, 2016). The respective values of $\Delta \mathrm{H}^{\circ}$ and $\Delta \mathrm{S}^{\circ}$ are obtained from the slope and the intercept respectively by plotting the Van't Hoff line from $\mathrm{ln} \mathrm{kc}$ versus $1 / \mathrm{T}$ (Figure 8). Another way of calculating the above-mentioned parameters is plotting $\Delta \mathrm{G}^{\circ}$ versus $\mathrm{T}$, where from the resulting straight line the slope is $\Delta \mathrm{H}^{\circ}$ and the intercept represents $\Delta \mathrm{S}^{\circ}$ (Figure 9) (Ekebafe, Ogbeifun, \& Okieimen, 2017). 


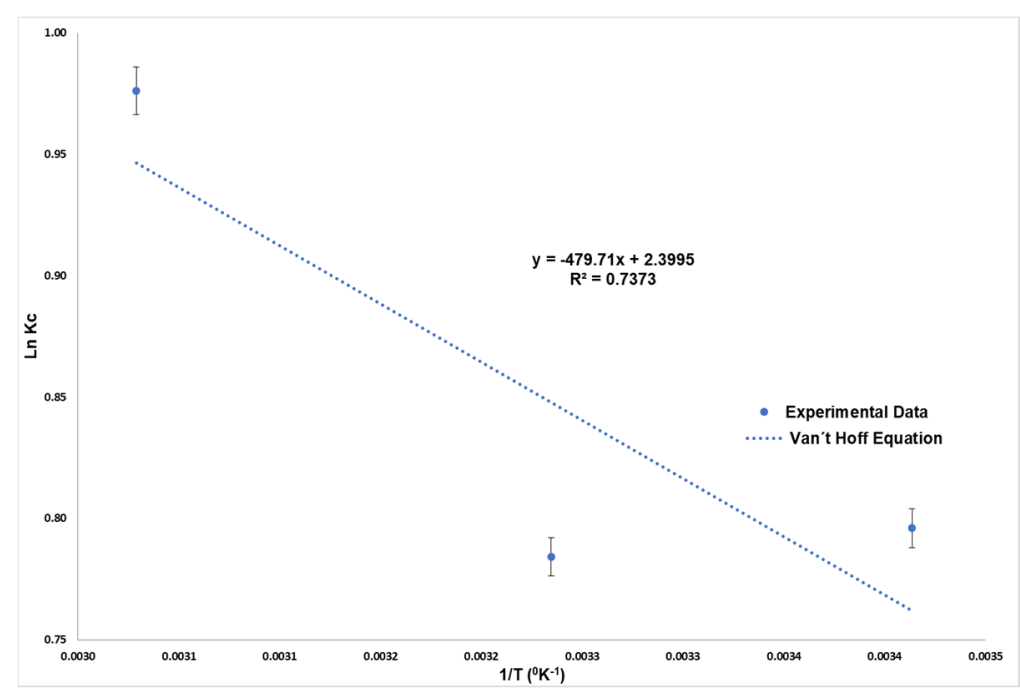

Figure 8. Adsorption Thermodynamics Parameters of $\mathrm{Cu}(\mathrm{II})$ onto Zeolite

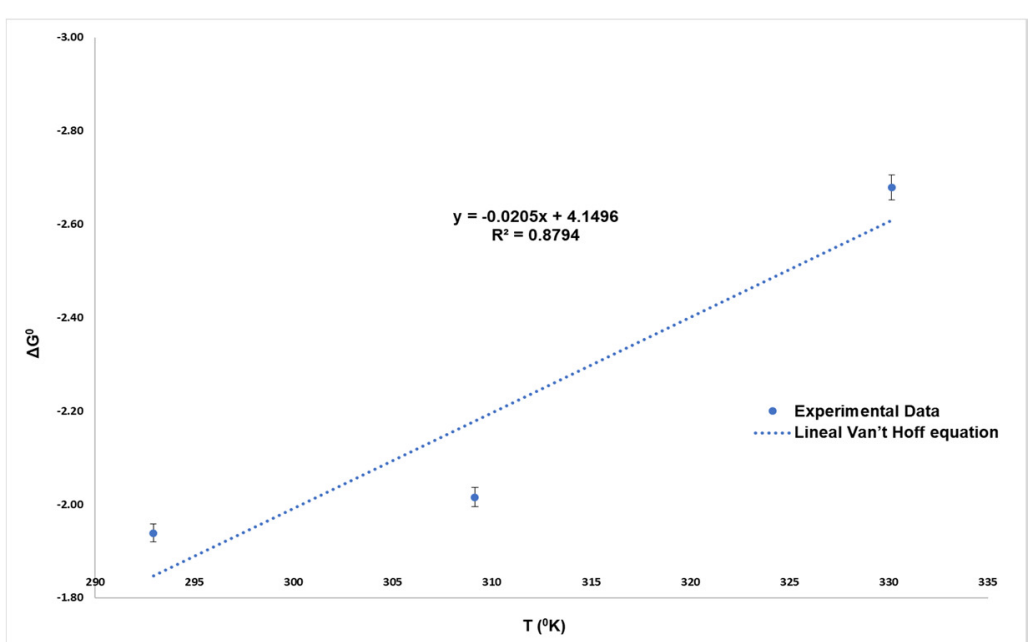

Figure 9. Adsorption Thermodynamics Parameters of $\mathrm{Cu}(\mathrm{II})$ onto Zeolite

Negative values in $\Delta \mathrm{G}^{\circ}$ (Table 4) indicate a spontaneous nature in the adsorption process and given that the values are more negative with the increase in temperature, they indicate that the increase in temperature favors the adsorption process. Ksakas et. al. (2018) reported that the negative values of $\Delta \mathrm{G}^{\circ}$ indicate that the adsorption is thermodynamically spontaneous and feasible, which agrees with the results of this study.

Table 4. Thermodynamic parameters for the adsorption of $\mathrm{Cu}(\mathrm{II})$ onto Zeolite

\begin{tabular}{|c|c|c|c|c|}
\hline $\mathrm{T}(\mathrm{K})$ & $\Delta \mathrm{G}^{0}\left(\mathrm{KJ} \mathrm{mo}^{-1}\right)$ & $\Delta \mathrm{H}^{0}\left(\mathrm{KJ} \mathrm{mo}^{-1}\right)$ & $\Delta \mathrm{S}^{0}\left(\mathrm{KJ} \mathrm{mo}^{-1} \mathrm{~K}^{-1}\right)$ & $\mathrm{Ea}\left(\mathrm{KJ} \mathrm{mol}^{-1}\right)$ \\
\hline 292.95 & -1.94 & 3.9883 & 0.0199 & 57.70 \\
\hline 309.15 & -2.02 & & & \\
\hline 330.15 & -2.68 & & & \\
\hline
\end{tabular}

When negative values are presented in $\Delta \mathrm{H}^{\circ}$, it indicates that the process is exothermic, while positive values indicate an endothermic process. When positive values are presented in $\Delta \mathrm{S}^{\circ}$ (Table 4), they indicate an increase in the randomness in the liquid-solid interface of the system during the adsorption process (Bouhamed, Elouear, \& Bouzid, 2012; Demiral \& Güngör, 2016). In general, when the absolute Gibbs free energy change is between 20 and $0 \mathrm{KJ} \mathrm{mol}^{-1}$, it is a physical adsorption; while for chemical adsorption it is in the range of -80 to $-400 \mathrm{KJ}$ mol $^{-1}$ (Özcan et al., 2004; Yu, Zhuang, \& Wang, 2001). In the results of the present study, positive values of $\Delta H^{\circ}$ were obtained, which indicates the endothermic nature of the adsorption. In the case of this study, the positive values of $\Delta \mathrm{S}^{\circ}$ reflect the affinity of $\mathrm{Cu}(\mathrm{II})$ and indicate the increase in randomization at the solid-liquid interface during the adsorption process, this being consistent with that observed by Ksakas et. al. (2018).

3.3.1 Estimation of Activation Energy

The magnitude of the activation energy gives an idea of the type of adsorption that is being carried out. There are two main types of adsorption: physical and chemical. In activated chemical adsorption the rate varies with temperature according to a finite activation energy $\left(8.4-83.7 \mathrm{~kJ} \mathrm{~mol}^{-1}\right)$ in the Arrhenius equation. In non-activated 
chemical adsorption, the activation energy is close to zero (Han et al., 2009). The activation energy for the adsorption in Zeolite was calculated with the Arrhenius equation:

$$
K c=K_{0} \exp \left(-\frac{E a}{R T}\right)
$$

Where: $\mathrm{k}_{0}$ is the independent temperature factor $\left(\mathrm{g} \mathrm{mg}^{-1} \mathrm{~min}^{-1}\right)$; Ea is the apparent activation energy of the adsorption reaction $\left(\mathrm{kJ} \mathrm{mol}^{-1}\right)$.

The linear form of the equation is expressed as:

$$
\ln K c=-\frac{E a}{R} \frac{1}{T}+\ln K_{0}
$$

Plotting Ln Kc versus 1/T gives a straight line with a slope equal to -Ea/R (Figure 8). The values of Ea are shown in Table 4. As the obtained value is higher than 8.4 and lower than $83.7 \mathrm{KJ} \mathrm{mol}^{-1}$, the adsorption is of the activated chemical type. The positive values of Ea suggest that an increase in temperature favored adsorption and the process had an endothermic nature (Han et al., 2009). The results of this study for activation energy indicate that the process can be carried out satisfactorily (Panayotova, 2001) and the results obtained do not show significant differences with what was found by Panayotova (2001) and according to this it is indicative that said process is of spontaneous nature. The results obtained are consistent with results previously obtained with other adsorbent materials (Panayotova, 2001). The values found for thermodynamic parameters in the results of the present study are within the same range as those observed by Panayotova (2001).

\section{Conclusions}

The Kinetic process was predicted in the following order: Pseudo-second order $>$ Elovich $>$ Intra-particle $>$ Pseudo-first order. Thermodynamic parameters indicate that the process is spontaneous and endothermic in nature. An increase in temperature favors removal. Copper removal is feasible through a Zeolite that was subjected to intense acid treatment. The adsorption is of the activated chemical type according to $\mathrm{E}_{\mathrm{a}}$. According to what was observed in the micrography, the zeolites did not suffer significant changes due to an intense acid treatment.

\section{Acknowledgement}

We are grateful to National Council for Science and Technology (CONACYT) for the support for the development of the project: Sustainable strategies for the mitigation of environmental impacts of mining activity in urban-rural areas, Proposals to remedy pollution (project number 2016-01-4104), Faculty of Zootechnics and Ecology, Autonomous University of Chihuahua, Rafael Escobedo Bautista, Alfredo Campos Trujillo, Silvia Miranda Navarro, Karla Campos Venegas and to all the people who with their comments enriched this work.

\section{References}

Abdel Salam, O. E., Reiad, N. A., \& ElShafei, M. M. (2011). A study of the removal characteristics of heavy metals from wastewater by low-cost adsorbents. Journal of Advanced Research, 2(4), $297-303$. https://doi.org/10.1016/j.jare.2011.01.008

Abdolali, A., Ngo, H. H., Guo, W., Lu, S., Chen, S. S., Nguyen, N. C., Wu, Y. (2016). A breakthrough biosorbent in removing heavy metals: Equilibrium, kinetic, thermodynamic and mechanism analyses in a lab-scale study. Science of the Total Environment. https://doi.org/10.1016/j.scitotenv.2015.10.095

Al-Degs, Y. S., El-Barghouthi, M. I., El-Sheikh, A. H., \& Walker, G. M. (2008). Effect of solution pH, ionic strength, and temperature on adsorption behavior of reactive dyes on activated carbon. Dyes and Pigments, 77(1), 16-23. Retrieved from https://www.sciencedirect.com/science/article/pii/S0304389408013770

Bouhamed, F., Elouear, Z., \& Bouzid, J. (2012). Adsorptive removal of copper ( II ) from aqueous solutions on activated carbon prepared from Tunisian date stones : Equilibrium, kinetics and thermodynamics. Journal of the Taiwan Institute of Chemical Engineers, 43(5), 741-749. https://doi.org/10.1016/j.jtice.2012.02.011

Chang, R., \& Goldsby, K. (2013). Química. (McGraw-Hill/Interamericana, Ed.) (11th ed.).

Demiral, H., \& Güngör, C. (2016). Adsorption of copper(II) from aqueous solutions on activated carbon prepared from grape bagasse. Journal of Cleaner Production, 124, 103-113. https://doi.org/10.1016/J.JCLEPRO.2016.02.084

Douven, S., Paez, C. A., \& Gommes, C. J. (2015). The range of validity of sorption kinetic models. Journal of Colloid and Interface Science, 448, 437-450. https://doi.org/10.1016/j.jcis.2015.02.053

Ekebafe, L. O., Ogbeifun, D. E., \& Okieimen, F. E. (2017). Equilibrium, Kinetic and Thermodynamic Studies Of Lead (II) Sorption on Hydrolyzed Starch Graft Copolymers. Journal of Polymers and the Environment, 26(2), 807-818. https://doi.org/10.1007/s10924-017-0949-x

Environmental Protection Agency. (2014). Reference Guide to Treatment Technologies for Mining-Influenced Water. Environmental Protection Agency (EPA).

Erdem, B., Özcan, A., Gök, Ö., \& Özcan, A. S. (2009). Immobilization of 2,2'-dipyridyl onto bentonite and its adsorption behavior of copper(II) ions. Journal of Hazardous Materials, 163(1), 418-426. https://doi.org/10.1016/j.jhazmat.2008.06.112 
Fardjaoui, N. E. H., El Berrichi, F. Z., \& Ayari, F. (2017). Kaolin-issued zeolite A as efficient adsorbent for Bezanyl Yellow and Nylomine Green anionic dyes. Microporous and Mesoporous Materials, 243, 91-101. https://doi.org/10.1016/j.micromeso.2017.01.008

Feng, N., Guo, X., \& Liang, S. (2009). Adsorption study of copper (II) by chemically modified orange peel. Journal of Hazardous Materials, 164(2-3), 1286-1292. https://doi.org/10.1016/j.jhazmat.2008.09.096

Ghasemi, M., Javadian, H., Ghasemi, N., Agarwal, S., \& Kumar, V. (2016). Microporous nanocrystalline NaA zeolite prepared by microwave assisted hydrothermal method and determination of kinetic, isotherm and thermodynamic parameters of the batch sorption of Ni ( II ). Journal of Molecular Liquids, 215, 161-169. https://doi.org/10.1016/j.molliq.2015.12.038

Gupta, S. S., \& Bhattacharyya, K. G. (2011). Kinetics of adsorption of metal ions on inorganic materials: A review. Advances in Colloid and Interface Science, 162(1-2), 39-58. https://doi.org/10.1016/j.cis.2010.12.004

Gupta, V. K. (2015). Bioadsorbents for remediation of heavy metals : Current status and their future prospects. Environ. Eng. Res, 20(1), 1-18.

Gupta, V. K., Mittal, A., \& Mittal, J. (2012). RSC Advances Batch and bulk removal of hazardous colouring agent Rose Bengal by adsorption techniques using bottom ash as adsorbent. RSC Advances, 2, 8381-8389. https://doi.org/10.1039/c2ra21351f

Hamidpour, M., Kalbasi, M., Afyuni, M., Shariatmadari, H., Holm, P. E., \& Hansen, H. C. B. (2010). Sorption hysteresis of $\mathrm{Cd}(\mathrm{II})$ and $\mathrm{Pb}(\mathrm{II})$ on natural zeolite and bentonite. Journal of Hazardous Materials, 181(1-3), 686-691. https://doi.org/10.1016/j.jhazmat.2010.05.067

Han, R., Zhang, J., Han, P., Wang, Y., Zhao, Z., \& Tang, M. (2009). Study of equilibrium, kinetic and thermodynamic parameters about methylene blue adsorption onto natural zeolite. Chemical Engineering Journal, 145(3), 496-504. https://doi.org/10.1016/j.cej.2008.05.003

Ho, Y. S. (2004). Citation review of Lagergren kinetic rate equation on adsorption reactions. Scientometrics, 59(1), 171-177. https://doi.org/10.1023/B:SCIE.0000013305.99473.cf

Ho, Y. S., \& Mckay, G. (1998). A Comparison of Chemisorption Kinetic Models Applied to Pollutant Removal on Various Sorbents. Trans IChemE, 76(November), 332-340.

Kankrej, S. R., Kulkarni, M. S., \& Borhade, A. V. (2017). Adsorption Isotherms, Thermodynamics, Kinetics and Mechanism for the Removal of $\mathrm{Ca} 2+, \mathrm{Mg} 2+$ and $\mathrm{Cu} 2+$ Ions onto Nosean Prepared by using Coal Fly Ash. Journal of Environmental Chemical Engineering, 6(2), 2369-2381. https://doi.org/https://doi.org/10.1016/j.jece.2017.12.048

Kaur, G., Couperthwaite, S. J., Hatton-Jones, B. W., \& Millar, G. J. (2018). Alternative neutralisation materials for acid mine drainage treatment. Journal of Water Process Engineering, 22(November 2017), 46-58. https://doi.org/10.1016/j.jwpe.2018.01.004

Kefeni, K. K., Msagati, T. A. M., \& Mamba, B. B. (2017). Acid mine drainage: Prevention, treatment options, and resource recovery: A review. Journal of Cleaner Production, 151, 475-493. https://doi.org/10.1016/j.jclepro.2017.03.082

Kim, N., Park, M., \& Park, D. (2015). A new efficient forest biowaste as biosorbent for removal of cationic heavy metals. Bioresource Technology, 175, 629-632. https://doi.org/10.1016/j.biortech.2014.10.092

Largitte, L., \& Pasquier, R. (2016). A review of the kinetics adsorption models and their application to the adsorption of lead by an activated carbon. Chemical Engineering Research and Design, 109. https://doi.org/10.1016/j.cherd.2016.02.006

Li, X., Zhou, H., Wu, W., Wei, S., Xu, Y., \& Kuang, Y. (2015). Studies of heavy metal ion adsorption on Chitosan/Sulfydryl-functionalized graphene oxide composites. Journal of Colloid and Interface Science, 448. https://doi.org/10.1016/j.jcis.2015.02.039

Ltaief, O. O., Siffert, S., Fourmentin, S., \& Benzina, M. (2015). Synthesis of Faujasite type zeolite from low grade Tunisian clay for the removal of heavy metals from aqueous waste by batch process: Kinetic and equilibrium study. Comptes Rendus Chimie, 18(10), 1123-1133. https://doi.org/https://doi.org/10.1016/j.crci.2015.03.013

Malamis, S., \& Katsou, E. (2013). A review on zinc and nickel adsorption on natural and modified zeolite , bentonite and vermiculite: Examination of process parameters, kinetics and isotherms. Journal of Hazardous Materials, 252-253, 428-461. https://doi.org/10.1016/j.jhazmat.2013.03.024

Moodley, I., Sheridan, C. M., Kappelmeyer, U., \& Akcil, A. (2018). Environmentally sustainable acid mine drainage remediation: Research developments with a focus on waste/by-products. Minerals Engineering, 126(November 2017), 207-220. https://doi.org/10.1016/j.mineng.2017.08.008

Motsi, T., Rowson, N. A., \& Simmons, M. J. H. (2011). International Journal of Mineral Processing Kinetic studies of the removal of heavy metals from acid mine drainage by natural zeolite. International Journal of Mineral Processing, 101(1-4), 42-49. https://doi.org/10.1016/j.minpro.2011.07.004

Moussout, H., Ahlafi, H., Aazza, M., \& Maghat, H. (2018). Critical of linear and nonlinear equations of pseudofirst order and pseudo-second order kinetic models. Karbala International Journal of Modern Science, 4(2), 
244-254. https://doi.org/10.1016/j.kijoms.2018.04.001

Oren, A. H., \& Kaya, A. (2006). Factors affecting adsorption characteristics of Zn2+ on two natural zeolites. Journal of Hazardous Materials, 131(1-3), 59-65. https://doi.org/10.1016/j.jhazmat.2005.09.027

Özcan, A. S., Erdem, B., \& Özcan, A. (2004). Adsorption of Acid Blue 193 from aqueous solutions onto Na bentonite and DTMA - bentonite. Journal of Colloid and Interface Science, 280, 44-54. https://doi.org/10.1016/j.jcis.2004.07.035

Panayotova, M. I. (2001). Kinetics and thermodynamics of copper ions removal from wastewater by use of zeolite. Waste Management, 21(7), 671-676. https://doi.org/10.1016/S0956-053X(00)00115-X

Park, D., Yun, Y.-S., \& Park, J. M. (2010). The past, present, and future trends of biosorption. Biotechnology and Bioprocess Engineering, 15(1), 86-102. https://doi.org/10.1007/s12257-009-0199-4

Park, I., Tabelin, C. B., Jeon, S., Li, X., Seno, K., Ito, M., \& Hiroyoshi, N. (2018). A review of recent strategies for acid mine drainage prevention and mine tailings recycling. Chemosphere, 219, 588-606. https://doi.org/10.1016/j.chemosphere.2018.11.053

Park, J. H., Ok, Y. S., Kim, S. H., Cho, J. S., Heo, J. S., Delaune, R. D., \& Seo, D. C. (2016). Competitive adsorption of heavy metals onto sesame straw biochar in aqueous solutions. Chemosphere, 142. https://doi.org/10.1016/j.chemosphere.2015.05.093

Puigdomenech, I. (2000). Windows software for the graphical presentation of chemical speciation. In AMER CHEMICAL SOC. (Ed.), ABSTRACTS OF PAPERS OF THE AMERICAN CHEMICAL SOCIETY (Vol. 219, pp. U760-U760). 1155 16TH ST, NW, WASHINGTON, DC 20036 USA.

Rajabi, M., Mirza, B., Mahanpoor, K., Mirjalili, M., Najafi, F., Moradi, O., ... Gupta, V. K. (2016). Adsorption of malachite green from aqueous solution by carboxylate group functionalized multi-walled carbon nanotubes: Determination of equilibrium and kinetics parameters. Journal of Industrial and Engineering Chemistry, 34, 130-138. https://doi.org/10.1016/j.jiec.2015.11.001

Rezaei, H. (2016). Biosorption of chromium by using Spirulina sp. Arabian Journal of Chemistry, 9(6), 846-853. https://doi.org/10.1016/j.arabjc.2013.11.008

Ryu, S., Naidu, G., Johir, M. A. H., Choi, Y., Jeong, S., \& Vigneswaran, S. (2019). Acid mine drainage treatment by integrated submerged membrane distillation-sorption system. Chemosphere, 218, 955-965. https://doi.org/10.1016/j.chemosphere.2018.11.153

Santos, R. M. M. dos, Gonçalves, R. G. L., Constantino, V. R. L., Santilli, C. V., Borges, P. D., Tronto, J., \& Pinto, F. G. (2017). Adsorption of Acid Yellow 42 dye on calcined layered double hydroxide: Effect of time, concentration, $\mathrm{pH}$ and temperature. Applied Clay Science, 140, 132-139. https://doi.org/10.1016/j.clay.2017.02.005

Shukla, P. R., Wang, S., Ang, H. M., \& Tadé, M. O. (2009). Synthesis , characterisation, and adsorption evaluation of carbon-natural-zeolite composites. Advanced Powder Technology, 20(3), 245-250. https://doi.org/10.1016/j.apt.2009.02.006

Song, X., Wang, S., Chen, L., Zhang, M., \& Dong, Y. (2009). Effect of pH, ionic strength and temperature on the sorption of radionickel on Na-montmorillonite. Applied Radiation and Isotopes, 67(6), 1007-1012. https://doi.org/10.1016/j.apradiso.2009.02.085

Subramani, S. E., \& Thinakaran, N. (2017). Isotherm, kinetic and thermodynamic studies on the adsorption behaviour of textile dyes onto chitosan. Process Safety and Environmental Protection, 106, 1-10. https://doi.org/10.1016/j.psep.2016.11.024

Wu, Y., \& Wang, L. (2016). Kinetic and Thermodynamic Studies of the Biosorption of Ni(II) by Modified Rape Straw. Procedia Environmental Sciences, 31, 75-80. https://doi.org/10.1016/j.proenv.2016.02.010

Yagub, M. T., Sen, T. K., Afroze, S., \& Ang, H. M. (2014). Dye and its removal from aqueous solution by adsorption: A review. Advances in Colloid and Interface Science, 209, 172-184. https://doi.org/10.1016/j.cis.2014.04.002

Yari, M., Rajabi, M., Moradi, O., Yari, A., Asif, M., Agarwal, S., \& Gupta, V. K. (2015). Kinetics of the adsorption of $\mathrm{Pb}(\mathrm{II})$ ions from aqueous solutions by graphene oxide and thiol functionalized graphene oxide. Journal of Molecular Liquids, 209, 50-57. https://doi.org/10.1016/j.molliq.2015.05.022

Yu, Y., Zhuang, Y. Y., \& Wang, Z. H. (2001). Adsorption of water-soluble dye onto functionalized resin. Journal of Colloid and Interface Science, 242(2), 288-293. https://doi.org/https://doi.org/10.1006/jcis.2001.7780

Zanin, E., Scapinello, J., de Oliveira, M., Rambo, C. L., Franscescon, F., Freitas, L., ... Dal Magro, J. (2017). Adsorption of heavy metals from wastewater graphic industry using clinoptilolite zeolite as adsorbent. Process Safety and Environmental Protection, 105, 194-200. https://doi.org/https://doi.org/10.1016/j.psep.2016.11.008

Zhang, Y., Jin, F., Shen, Z., Lynch, R., \& Al-Tabbaa, A. (2018). Kinetic and equilibrium modelling of MTBE (methyl tert-butyl ether) adsorption on ZSM-5 zeolite: Batch and column studies. Journal of Hazardous Materials, 347, 461-469. https://doi.org/https://doi.org/10.1016/j.jhazmat.2018.01.007 